\title{
Considerations from the Development of a Local Spatial Data Infrastructure
}

\author{
Clodoveu A. Davis Jr. \\ Instituto de Informática \\ Pontifícia Universidade Católica de Minas Gerais \\ Brazil \\ clodoveu@pucminas.br
}

\author{
Frederico T. Fonseca \\ School of Information Sciences and Technology \\ The Pennsylvania State University \\ U.S.A. \\ ffonsecalist.psu.edu
}

\begin{abstract}
The development of spatial data infrastructures is often the victim of an excessive focus on data and standards. In this paper we use the hermeneutics of Gadamer and Habermas to understand the problem of how spatial data infrastructures (SDI) can succeed, both in emergent and developed countries. We use Gadamer's concept of phronesis to show how being an application-driven project is a key for success, and Habermas' view of knowledge to show the importance of emancipatory knowledge (a form of knowledge that combines practical and technical knowledge) in the implementation of SDIs in transitional economies. A case study on a GIS project in Belo Horizonte, Brazil, is presented. The project has been continuously evolving for fifteen years, even though it started with a focus on data and standards, and generated a strong and active spatial data infrastructure for the city. The reasons for success were manifold, but we highlight the application-driven nature of the project and the combination of multiple disciplines and multiple levels of expertise (ranging from practical to theoretical) in the team responsible for its design and implementation.
\end{abstract}

\section{Introduction}

In the call for papers for this special issue, Georgiadou et al. (2004) warn us that both theory and practice of current research into SDIs focus "strongly on issues related to spatial data and their accessibility (for example, issues of standards and interoperability)" and contribute "significantly to the unrealized benefits of SDI". Although we agree with them in that a strong focus on data is a frequent cause of failure as can be seen in the GIS literature, we present in this paper a project that succeeded in a transitional economy (Brazil) despite having started with an enormous investment in data and with its first project being directed to data exchange. Why did such a project succeed? What were the causes that avoided failure and led to a strong and thriving spatial data infrastructure? These are the questions that this paper will address based on two assumptions. First, we understand that knowledge is decisive to the development of transitional economies. Second, we discuss a hermeneutic view that knowledge, by itself, without an application, is meaningless. The knowledge that is needed by transitional economies is applied knowledge. Notice, however, that this problem also occurs in developed economies, where sustainability of IT projects is not a trivial issue. This paper will show that many solutions that have been adopted in Brazil could also be applied in developed countries.

There is a consensus that knowledge is decisive for development. Economies are created and sustained on the foundation of information, learning, and adaptation, and not only with the accumulation of physical capital. Nevertheless, creating, acquiring, and using scientific and technological knowledge in developing countries is a Sisyphean task 
(Sagasti 2004). A key component in the implementation of information and communication technologies (ICTs) in transitional economies is what Braa et al. (2004) call sustainability. It is "the challenge to make an information system work, in practice, over time, in a local setting. This involves shaping and adapting the systems to a given context, cultivating local learning processes, and institutionalizing routines of use that persist over time (as well as when the researchers leave and external funding is over)" (p.338). One of the requirements for the sustainability of technological projects in developing countries is that indigenous knowledge and techniques are respected, maintained and included in the process of implementation of new technologies. The new technologies have to be seized upon and appropriated if they are to serve the goals of social and human development in these countries. Otherwise, the knowledge paradigm will only increase the already alarming levels of exclusion and inequality (Reed 2000).

We argue that Belo Horizonte's GIS project (GIS-BH), our case study, is such a case, in which knowledge was appropriated and applied to local conditions. In order to understand why it succeeded we will use Gadamer's hermeneutic approach to knowledge, presented in Truth and Method (Gadamer 1975), and Habermas' three types of knowledge, as laid out in Knowledge and Human Interests (Habermas 1971). In his work, Gadamer studies Aristotle and the concept of techne, the knowledge "of a craftsman that is able to make some specific thing" (p.281). But a broader knowledge, one that can be applied to social situations, has to be a knowledge of a dynamic kind, one that determines and guides action. Consequently it "must include the application of knowledge to the particular task" (p.281). We will argue here that, in the project we study, applications were the driver of everything. Although the project had an early focus on data and standards, the fact that it was application-driven made it successful. We define applications here in the hermeneutic sense, which is broader than the software application sense, although both are related. Gadamer considers "application to be as integral a part of the hermeneutical act as are understanding and interpretation" (p.275). We apply to the understanding and assimilation of technology[LB1] what he is saying about the understanding of texts. "This includes the fact that the text (the technology, our parenthesis), whether law or gospel, if it is to be understood properly, i.e. according to the claim it makes, must be understood at every moment, in every particular situation, in a new and different way. Understanding here is always application" (p.275).

We will discuss the development of a local SDI from the perspective of the GIS-BH project, from the city of Belo Horizonte, Brazil. It is a nationally-recognized initiative, known for its pioneering nature and innovative proposals, with an emphasis on social applications. GIS-BH also stands out for having established, early in the project, a cooperation agreement with numerous partners for costless data exchange and distribution. Such a broad cooperation increased the quantity and the variety of applications, thus exerting a stabilizing effect and pushing the GIS towards becoming a spatial data infrastructure (SDI) on urban data. The bottom-up, applications-driven approach that led the project to achieve the present stage of development is the focus of this paper.

This paper is organized as follows. Section 2 presents a brief theoretical discussion on the process of knowledge acquisition and sustainability, which is central to the arguments presented here. Section 3 presents the development of GIS-BH, pointing out 
elements and key events that can kelp understanding its success. Section 4 presents the link between our theoretical concepts and the real project. Section 5 presents a set of recommendations for similar projects. Finally, section 6 presents our conclusions and indicates directions for fut ure work on this subject.

\section{Moving from Techne to Phronesis}

Central to the hermeneutic approach proposed by Gadamer, and very important for our analysis of the acquisition and sustainability of knowledge in a transitional economy, is the fact that a given tradition or practice must be understood again and again, depending on the context and situation. A common situation in the attempts to establish SDIs in transitional economies is the use of packages funded by international agencies. This kind of solution makes an intensive use of foreign expertise, which often lacks a deeper knowledge of local conditions.

Understanding, Gadamer says, is "a special case of applying something universal to a particular situation" (p.278). In order to understand this problem, Gadamer uses the concept of phronesis from Aristotle. Practical knowledge, or phronesis, is a special kind of knowledge, as opposed to techne and episteme. Phronesis is knowledge directed towards a concrete situation, while episteme is "scientific knowledge, knowledge of what is universal, of what exists invariably" (Bernstein 1983). Techne corresponds to technical know-how, and can be learned and forgotten, while ethical reasons cannot. Gadamer's intention was to show that knowledge cannot be understood by itself. Instead, it must not be "detached from a being that is becoming" but it is "determined by it and determinative of it" (p. 312).

Also related to Gadamer's position is the idea of knowledge as a fundamental component in development. A World Bank report (The World Bank 1999) suggests two views of knowledge. First, knowledge about technology, technical knowledge or knowhow. This is the software engineering aspect of SDI. Second, knowledge about attributes. This is knowledge about the needs and local conditions. The lack of the latter generates "information problems" (The World Bank 1999). This perspective of knowledge refers to the results of the use of technology. These results should include geographic information systems that address information issues of public health, transportation, security, and other matters of interest of developing countries.

Habermas (1971) has a more precise elaboration of knowledge and of how it can be used as an emancipatory instrument. For him, knowledge can be seen in three different categories. First, there is "information that expands our power of technical control" (p. 313). Second, there are "interpretations that make possible the orientation of action within common traditions" (p. 313). And finally, and more importantly, there are "analyses that free consciousness from its dependence on hypostatized powers" (p. 313). Habermas (1971) names the three categories of possible knowledge as technical, practical, and emancipatory. Emancipatory knowledge is achieved by the combination of the other two types of knowledge. We argue that emancipatory knowledge will be acquired by developing countries through an adequate use of the technology. Our expectation about the potential use of SDIs in transitional economies can also be seen as an extension of Habermas' position about the possible kinds of knowledge. We argue that 
in order to be successful in transitional economies, SDIs have to play the role of emancipatory knowledge.

This is precisely the case in GIS-BH, in which the need to stabilize the project, both politically and financially, along with the need to ensure continuity and sustainability, caused the project to be developed in a bottom- up and application-driven fashion. As the detailed account presented in the next section shows, even though the project's initial goals were ambitious, their realization took place over a long time - over fifteen years -, through a succession of cautious, localized, and often negotiated actions that created and maintained a favorable environment for the development and expansion of the GIS and its use.

\section{Belo Horizonte: From Mapping to GIS to SDI}

Belo Horizonte is the fourth largest Brazilian city, with a population of more than 2.2 million people, spread over 335 square kilometers, and is the center of a metropolitan area that houses over 3.5 million people. Belo Horizonte's GIS development effort has started in 1989, and is continuously evolving ever since. Throughout its history, GIS-BH has received awards, has been widely presented in the form of invited lectures at many events nationwide, and has generated a body of over 200 publications, including dissertations and theses, academic papers with technological and methodological innovations, conference papers about applications development, and technology dissemination articles. The project's priorities lie in social applications, including education, health, transportation, traffic and environmental control, among many others. The authors of this paper have both been members of the GIS-BH team for many years, and currently cooperate with their colleagues that are still working in the project through academic, technical, and personal links.

GIS-BH was created as part of the administration's response to the numerous new challenges presented by the 1988 Brazilian Constitution. The new constitution emphasized a shift of responsibilities from the Federal and State levels to the local level. Various public services, such as health, basic education, water and sewage, energy, transportation, and traffic were transferred from other levels of government to the municipalities, along with regulations and standards that placed additional pressure on them to be more responsive towards the demands of the citizens. Municipal governments were also expected to be much more accountable and transparent, providing detailed information to the public in order to allow the effective exercise of the democratic right of participation.

In the early nineties, many GIS projects were almost exclusively driven towards revenue increases, following a sales pitch presented by many vendors and consultants. According to these "specialists", deploying a GIS would cause enough revenue increases to pay for the entire technological investment in a very short time. In fact, methodological shortcomings and lack of consistent updating caused cadastral bases for taxing purposes to be quite outdated and flawed, thus data checking or updating effort were likely to have caused revenue increases anyway - regardless of the use of GIS. For that reason, most urban GIS projects in Brazil were led by tax collection departments, rather than by urban planning departments, or even by IT departments. 
In Belo Horizonte, GIS was developed at the municipal IT company (Prodabel), which was also responsible for the city's cartography. This unusual scope of activities enabled Prodabel, early in the project, to form a team of specialists in several IT areas (databases, information systems, computer graphics) as well as in fields such as urban cadastre, cartography, surveying and others.

Concern on multiple uses of the data was present early on the project. Ensuring the level of investments and political support required to push the project forward, at a time when this technology was largely unknown, required project managers to propose applications in many different areas. Project managers were also able to convince decision makers throughout the administration that a solid base map was required in order to provide adequate support for the thematic applications.

With this, Belo Horizonte's GIS faced, early on, three important challenges: (1) building a general-purpose database, (2) developing a wide range of applications, mostly in social fields, and (3) keeping this database up-to-date, as required by the applications (Davis Jr. and Zuppo 1995).

The first challenge is directly related to research in topics such as data transfer standards, evolving towards interoperability, and then on to semantics and ontologies. This caused part of Prodabel's GIS team to evolve into a research team, continuously seeking innovative approaches and solutions to all these themes, often in cooperation with universities and research centers (See (Davis Jr. 1995; Fonseca and Davis Jr. 1999; Fonseca, Egenhofer et al. 2000; Davis Jr. 2002; Fonseca, Egenhofer et al. 2002) for a sequence of research initiatives conducted along that path).

The second challenge regards arguably the most important aspect of GIS as a technological tool, which is its interdisciplinary nature. From this, the involvement of specialists from each application area was required, thus forcing the establishment of strong connections between Prodabel's original GIS team and thematic specialists in each of the city's departments, particularly in health, education, sanitation, transportation, planning and licensing. In each of these areas, GIS became a tool geared towards technical activities, used directly by technicians, with IT and base map support by Prodabel.

The third challenge required an approach being neither academic (as the first) nor integrational (as the second). Updating such a varied database (currently comprising over 6 million objects, distributed through over 300 object classes) required a strong coordination of efforts and cooperation with external agencies (utility companies, state government departments, federal institutions, universities, and others). In turn, this drive towards cooperation provoked an interest in data sharing among the municipal administration and these external actors, which expanded even more the range of GIS data and applications, thus forming a virtuous circle, leading to increased data quality, interoperability, and scale gains.

In this section, we describe the development of Belo Horizonte's GIS since 1989, showing in detail how these challenges (and others) were met, leading to what can be 
construed as the foundations of a true SDI for the city. We divide this period into three phases. The first phase corresponds to the initial capacity building, including initial data set creation, hardware and software acquisition, personnel training, and initial applications development. In the second phase, the GIS acquires more maturity, shifting the focus to sustainability through the deployment of a wide range of applications and the assurance of data quality through maintenance routines. The third phase corresponds to the maturity of the GIS, a phase in which the accumulation of knowledge and experience with urban GIS leads to a more secure definition of goals and to a vision of the role this technology can play in the future of local government. In this phase, a new technological architecture (Davis Jr. and Oliveira 2002) starts to replace hardware and software from the early 1990s, data sets are renewed, and an already wide cooperation agreement gains further momentum. Each of the phases will be described in detail through the next subsections.

\subsection{Initial Capacity Building (1989-1992)}

This phase began as soon as the decision was taken to create a new base map, in electronic form, for the city of Belo Horizonte. This base map was created from a new aerial survey, followed by extensive and detailed stereoplotting. At that time, this process was both costly and slow: it took more than two years to be complete, and cost over US\$ 1.00 per inhabitant.

Figure 1 shows, schematically, how this first phase evolved, considering three main aspects: development of the initial geographic database (GDB), establishment of cooperation, and technology acquisition. 


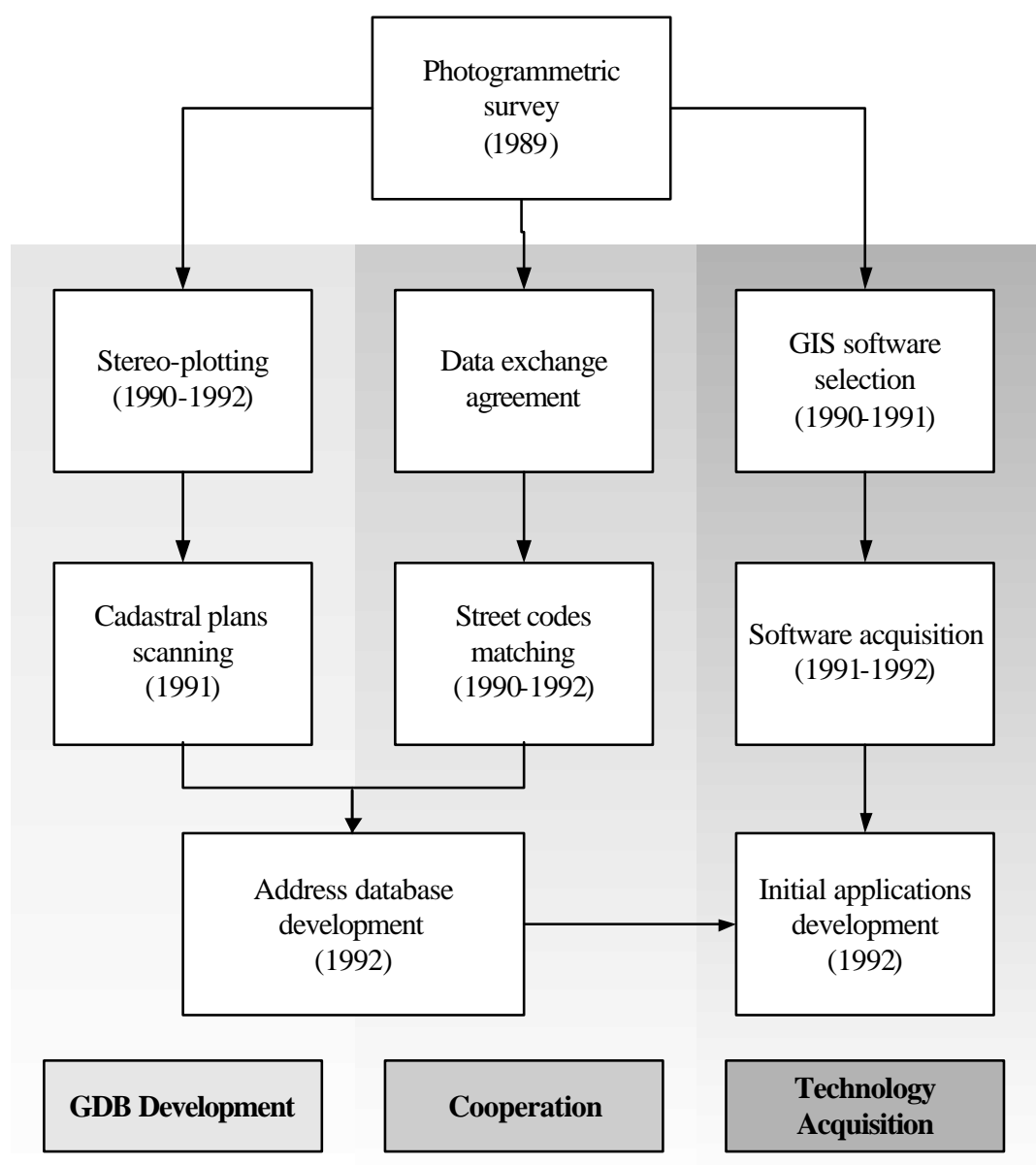

Figure 1 - Initial capacity building

While the stereoplotted data were being developed, Prodabel started a series of discussions with institutions and companies that were deemed as possible partners in the use and updating of the base map. This included the utility companies (power, water and sewage, telecom) plus several municipal, state, and federal organizations. In these discussions, the possibility of sharing the data resulting from the rather large investment in database creation acted as a catalyst to push cooperation forward. Even before a formal cooperation agreement was signed, some of the interested parties were already working informally with Prodabel, in order to develop a data set that was deemed as strategically important to all participants, and that would not result from the stereoplotting process: an address database. First, cooperation involved generating a compatibility table for street codes. Later, this evolved into the development of our first common address data set, with over 300,000 individual addresses, georeferenced as points (Davis Jr. 1993). The creation of the address database was further accelerated by the creation of an image data set by the scanning of the existing analogous cadastral plans. This element also helped us to accelerate the transition from the previous cadastral routines to the new system.

Also while the stereoplotted data were being generated, Prodabel's GIS group took on the creation of a request for proposals (RFP) for the acquisition of GIS software. In this RFP, technical features of existing products were compared to the project's 
expectations. Due to the lack of knowledge and to the lack of a fair ground for featureby-feature comparison, the RFP was finally published containing a very broad spectrum of good intentions, most of them application-based, and asked vendors for comments on how to accomplish those ideas using their products. As a result, Prodabel purchased a French GIS software (APIC), which was based on an object-oriented database, had a powerful query language, and included a number of innovative features (Davis Jr. and Borges 1994). Prodabel has been the sole user of that software in Brazil ever since. The need to communicate with other GIS users eventually led Prodabel's team to create a drive towards a more complete understanding of the fundamentals of GIS, therefore going much further than it would have been possible by simply learning the operational aspects of the software.

The installation of hardware, the training in APIC and the delivery of the initial data set from stereoplotting took place almost at the same time, late 1991 and early 1992 - just before a political change in Belo Horizonte's municipal administration, mandated by the October 1992 elections. This political factor was very important, since the large investment in data, hardware, and software, along with the wide discussions inside and outside the municipal administration, led to high expectations. Also, since the mayor was a former IT specialist, and thus able to fully understand the complexity of this process, the project had been quite well insulated from political turbulence - up to that point. Because of that, some initial applications were developed mostly to serve as "demos", to display the possibilities of this new technology. These applications were widely showcased, at every possible opportunity (conferences, expositions, political events, and so on), and even received a national award at a major environmental event.

At that time, however, even though all of the project's initiatives were working properly, some obstacles that could affect the progress of the project were becoming quite clear. First, the proprietary GIS solution purchased by Prodabel had a number of advantages on the technological side, but was somewhat difficult to integrate with other information systems. Also, since Prodabel was the only user, there was no source from which the company could hire development and training services. The solution envisioned at that time was to increase the investment in Prodabel's own personnel, and to identify as soon as possible a desktop GIS alternative to APIC, in order to increase the capillarity [LB2] of the GIS with reasonable costs. Another problem was the risk for investment discontinuity, mostly because of the upcoming elections. If investments failed at that phase of the project, serious problems could arise from the rapid deterioration of data quality, and difficulties to keep up with technological evolution. To counter this problem, a strategy to establish a firm foothold for the GIS in the municipal administration, through a wide diversity of applications, was established. Furthermore, specialists in each application's field were summoned to participate in the development efforts. At that stage, it was evident that a clear strategy for sustainability was required, thus inaugurating a new phase in the project.

\subsection{Sustainability Phase (1992-1995)}

The first response for the sustainability challenge took place intuitively, in the form of the cooperation agreement, which was under development while the first digital data set was 
being prepared. Even though an existing agreement with numerous external entities would help, sustaining the project evidently required a continuing expansion of the user base, and in turn that would only be achieved through more applications.

Figure 2 shows how this phase occurred, considering again three different aspects, as in Figure 1. First, the GDB construction went on, adding to the database a number of object classes that were important in a multi-applications environment, and corresponded to data that could not be collected by aerial photogrammetry. These included the most important elements of the urban infrastructure and services, street centerlines, and spatial reference units of all kinds (neighborhoods, health care districts, census sectors, planning sectors, and so on). The second aspect evolved from an emphasis on cooperation to some actions developed with the purpose of promoting the system's consolidation, through the widest possible dissemination. Prodabel's GIS team started to participate in many GIS conferences, nationally and internationally, and to publish articles on GIS concepts, development strategies, technology, maintenance, and other aspects in all sorts of publications. Regarding technology acquisition, in this phase Prodabel's multidisciplinary team became fully operational, and started to expand its reach through new technologies (such as desktop mapping, remote sensing, digital image processing, and others). Research initiatives began to take place, motivated by the early publications and participation in academic events, and fueled by the team's technical quality.

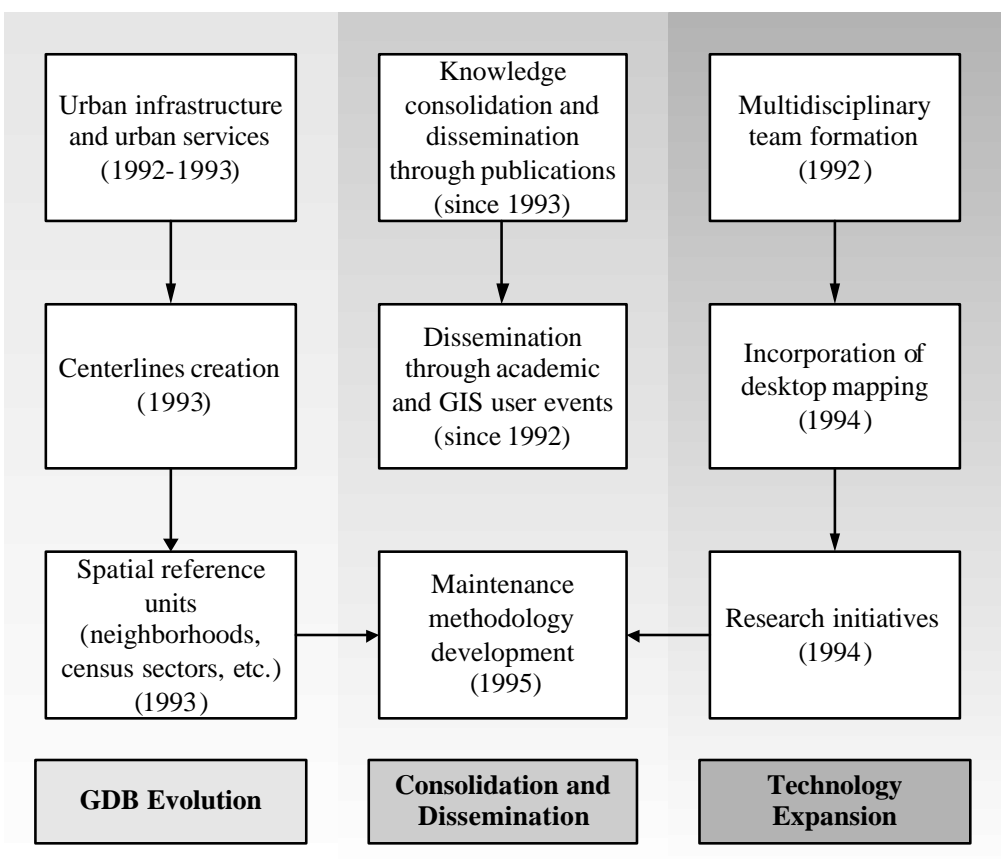

Figure 2 - Sustainability phase

A fundamental landmark of this phase is the development of a maintenance methodology for the digital data (Davis Jr. and Zuppo 1995). This methodology was developed as an adaptation of time-tested manual, paper-cartography-based routines, to incorporate GIS as a tool (Silva and Ottoni 1995). Since Prodabel's cadastral team had a large experience in field work, the maintenance methodology was created with most of 
the correct concerns in mind. The most important decision here was on prioritizing the maintenance of data that would potentially be shared among numerous applications. Data that were merely "cartographic", meaning object classes that were vectorized form aerial photos solely to fulfill cartographic standards, were not considered until some application determined its use and the adequate method for its maintenance. The development of this methodology serves as a classical example of the fusion of practical and technical knowledge, leading successfully to emancipatory knowledge.

In this phase, some data-related initiatives stand out, as early attempts to reach a higher level of integration between Prodabel and its partners. Members of the cooperation agreement conceived and agreed on a standard for data classification, which served as a base for a broad information catalog. This experience led, later on, to a state-wide geoinformation assets catalog. In this classification, data were regarded as being essential, if the information is required for the operation of a given organization, or complementary, if the information is useful for the organization, but is not mandatory for its activities. Parallel to that, data were classified as specific, if its generation and maintenance are part of the organization's institutional responsibility, or as common, if the information is usually obtained from external sources. There was also a classification based on levels of confidentiality and privacy (Davis Jr. 2002).

Regarding standards, in this phase an attempt was made to create a data interchange standard for the cooperation agreement, a data storage format called IIG. This standard was neutral in respect to existing GIS software, so that it would only be necessary for each partner to develop converters to/from their GIS from/to IIG, instead of relying on specific converters, developed for each pair of existing GISs, or on transferring data encoded in CAD format (Davis Jr. 1995; Davis Jr. 2002).

Agreements on data sharing were also reached in this phase. First, an agreement on street codes and addresses made it feasible to create a street code conversion table involving all the coding systems in use (Prodabel, power company, water and sewage company, telecommunications company, police, and postal codes). As a result, many of the partners revised their conventional information systems to reflect and to facilitate this integration. An agreement on the boundaries of some commonly used spatial information units was also developed in this phase.

To summarize, the sustainability phase was characterized by numerous efforts to stabilize, standardize, consolidate, and evolve with the GIS towards its original goals. This was achieved by deepening the emphasis on applications, by increasing the GIS team's technical capacity, and by extending the reach of the GIS data to as many partners and users as possible. Making good use of the investment in the GIS has driven these efforts, thus generating a successful strategy of turning something that was seen as expensive into something perceived as inherently valuable, inside and outside the municipal administration. 


\subsection{Maturity Phase (1995-today)}

The next phase of the project is characterized by extensive usage of GIS resources, and by a drive towards a new technological architecture (Davis Jr. and Oliveira 2002), through which the distribution of data and the integration with partners can be achieved with greater ease and flexibility.

Figure 3 shows a diagram of the main actions in this period. We can now consider database actions to be geared towards integration, since they mostly include general interest tems, such as a new high-resolution imagery set. We can also start mentioning definite sustainability efforts, which in this phase include greater capillarity [LB3]through the use of desktop mapping and, hopefully in the near future, Web GIS. A temporary solution to rapid and non-bureaucratic dissemination of data was the creation of a FTP server containing most of the shared data, with free access to municipal organizations and partners. This server was initially at Prodabel, but it has recently moved to a machine installed at Minas Gerais Federal University.

Regarding the technological aspects, in this phase we can actually say that Prodabel's research and development efforts started producing results, materialized as methodologies, in-depth studies, and experiments with issues that are clearly in the project's future. A geographic data modeling technique was proposed, and is currently used in many organizations throughout the country (Borges, Davis Jr. et al. 2001). A new architecture for the GIS was studied and is currently under implementation. This new architecture incorporates elements that allow it to be interoperable and distributed, and with a strong support for digital imagery (Davis Jr. and Oliveira 2002). Specialists at Prodabel are currently researching advanced subjects, such as process and action modeling through ontologies, visualization in large spatial and spatio-temporal databases, and service-oriented architectures. 


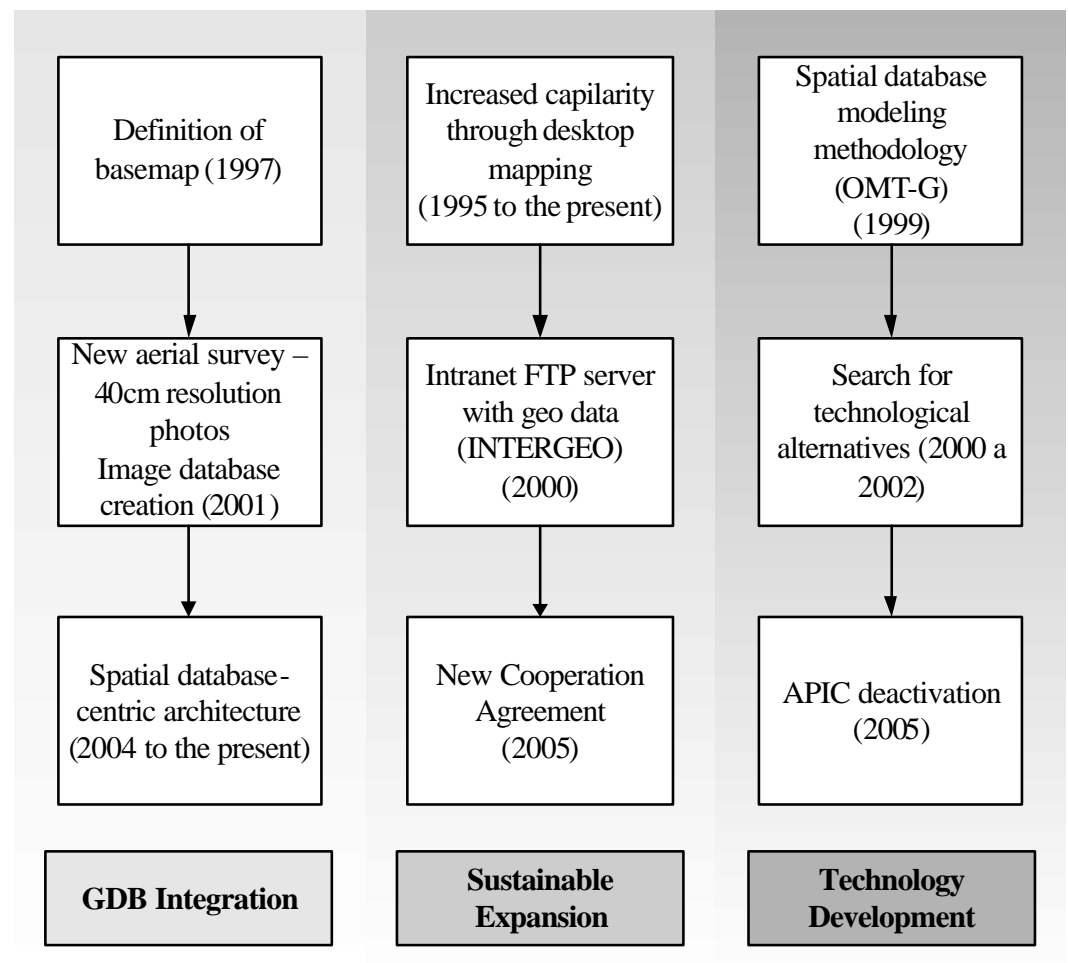

Figure 3 - Maturity[LB4] phase

Another maturity aspect is the scope and range of applications. GIS-BH started the millennium with several working applications, not mentioning punctual efforts and support to numerous city projects. Most of the applications cover social fields, and include, but are not limited to the following:

- Education: distribution of students among grammar schools based on spatial criteria. A pre-registration, in which the home address is recorded for each student, precedes the actual enrollment in a school. Based on the address, a school for enrollment is assigned to each student (Fonseca and Zuppo 1994; Pinto 1999).

- Health care: monitoring of epidemics and diseases propagated by vectors; monitoring of health-related social indicators (Sousa and Bretas 1994; Pessanha and Carvalho 1999).

- Transportation and traffic: creation and maintenance of the vehicle circulation network, including all circulation constraints; recording the location and contents of every traffic sign in the city; bus itineraries and stops; traffic accident mapping (Zuppo, Davis Jr. et al. 1996; Meinberg 2003).

- Sanitation: recording of all garbage collection and street sweeping routes; database of all public trash cans.

- Land use and zoning: a database containing the city's land use zones and associated parameters. 
- Parceling: reparceling and validation of illegally parceled areas; tools to compare actual parceling with proposed/approved parceling (Peixoto 2000).

- Urban planning: support for the development of Belo Horizonte's Master Development Plan and the creation of socio-economic indicators (Oliveira, Sousa et al. 1996).

- Public safety: crime mapping and analysis (by Minas Gerais State military police, PMMG).

- Water and sewage: complete networks (by Minas Gerais State water and sewage company, COPASA-MG).

- Drainage: complete network, with engineering and maintenance details.

- Power distribution: complete network (by Minas Gerais energy company, CEMIG).

- Public lighting: every lighting fixture's position recorded, along with lamp type.

- Favelas (slums): mapping, support in the creation of development plans.

- Economic activities: mapping, planning, concentration analysis (Oliveira 1997).

With such a wide variety of applications, and a significant number of partners, inside and outside the municipal administration, there was a clear need for a better arrangement as to the maintenance tasks. Prodabel remained in charge of coordinating the updating of every information class that is the potential object of interest from multiple users. With this, a decision was reached as to the contents of a "base map", or rather, a "basic information set". Basically, this basic information set includes address data, urban cadastre, most spatial reference units, digital cartographic data, demographics (Oliveira, Sousa et al. 1995), and imagery. Other municipal organizations or partners are in charge of updating information that is specific to their institutional responsibility.

With this, there are actually multiple updating efforts taking place in Belo Horizonte at the same time. For instance, a municipal company in charge of slum support and urbanization (URBEL) is currently acquiring a new imagery set with a $10 \mathrm{~cm}$ resolution. CEMIG, the state-owned power company, is revising a database on public lighting, after a process to replace mercury vapor with the more economical sodium light bulbs. Both databases are to be shared with other partners at the end of their development.

However, the maturity of GIS-BH is better demonstrated by looking at the cooperative efforts to maintain an important part of the basic information set: the address database. This cooperation started even before the GIS, with the compatibilization[LB5] of street codes we mentioned before. Currently, a group of professionals, representatives of every one of the 27 organizations that signed the cooperation agreement, meet every two weeks to discuss possible actions, to exchange knowledge on technical aspects, and to 
coordinate joint efforts. One of these efforts, recently concluded, involved several municipal organizations, along with the Brazilian census bureau (IBGE), the utility companies, the Brazilian postal services and a branch of the judiciary in order to revise and rebuild the addressing system in some favelas. This was performed with a very low investment, and extensive sharing of resources, including human resources: data collection was performed by health agents and judiciary police officials; training and methodological orientation was provided by IBGE; digitizing was performed by Prodabel; and other partners contributed with items such as bus tickets, vehicles, plotting and other items.

Currently, the cooperation efforts are backed by a new version of the original agreement, which was signed in 1993 . This new version essentially preserves the terms and definitions of its predecessor, and incorporates a new and easier process for the admittance of new partners. This agreement has been signed by 27 different organizations, at the municipal, state and federal governmental levels, plus private organizations that work on socially relevant fields and/or maintain shareable information on the city, which includes all privately-owned utility companies.

This kind of data, expertise, effort, and investment sharing initiatives, along with the wide availability of general-purpose data, in standard formats, available on-line, and housed at a "neutral" server, motivates us to begin thinking in terms of a SDI for Belo Horizonte. Actually, the cooperation (and the interdependence that results from it) among multiple partners, to support multiple applications, with multiple clients, correspond to what is expected of a real SDI. Technological barriers were once great, at the time every partner used a GIS from a different vendor. With new technological tools, such as spatial databases and interoperable Web-based GIS, these barriers started to diminish in importance, and future pro-SDI elements (we can mention research topics such as ontology-driven GIS, geospatial semantics, service-oriented architectures, OpenGIS standards, geospatial Web services, and many more) will reduce those barriers even further.

\section{Analysis: The Link between Theory and Practice}

In this section, we show how Habermas' three categories of possible knowledge, technical, practical, and emancipatory, are linked to the GIS-BH project. Then we discuss how application, in the hermeneutical sense, was fundamental in the project. We show where Gadamer's concepts of techne, episteme, and phronesis are to be found in our case study.

\subsection{Habermas' Emancipatory Knowledge in GIS-BH}

Habermas (1971) came up with his three types of knowledge when he was studying a way of preserving the theoretical aspects of science while at the same time keeping its roots on practical aspects. He says "knowledge of the apparently objective world of facts has its transcendental basis in the prescientific world. The possible objects of scientific analysis are constituted a priori in the self-evidence of our primary life world" (p.304). "Once the theoretical attitude has been adopted, it is capable in turn of being mediated with the practical attitude" (p.305). 
We start our analysis with practical knowledge. We consider that the knowledge about the data can be compared with practical knowledge. As we showed, the GIS project of Belo Horizonte started within the city department that was in charge of the city's cartography and urban cadastre. There was a long tradition of development and maintenance of cadastral information, even though most of it was maintained in nondigital form before the GIS deployment. Know-how on how to handle the data itself was already present. There was knowledge on how to do things in terms of geographical data.

The second type of knowledge analyzed by Habermas is technical knowledge. This kind of knowledge was present in two components of the GIS-BH project. The first one is the scientific education of the team in charge of the GIS project. All of them had a College education with degrees in Engineering, Computer Science and Business. Second, the project invested in science since its beginning, leading, years later, to a range of academic activities that include invited lectures at national and international meetings, publications, and even a professional masters program.

Our third and final component is emancipatory knowledge. The IT company, as well as its cartography and urban cadastre department, had a tradition of service prior to the start of the GIS project. Both had, as part of their basic mission, to fulfill and support the information needs of Belo Horizonte's local government and its citizens. Thus, we can relate our third knowledge component to the applications developed by the IT company and to the services provided by the cartography department, which later became a GIS department. It was the coexistence of practical and technical knowledge in the same place that generated the necessary balance to the creation of emancipatory knowledge.

\subsection{An Application-Driven Project}

Gadamer considers that understanding and interpretation, together with application, comprise one unified process. There can be no appropriation and understanding of technology without all three elements being present. We think that what leads many projects to fail and get stuck in the data and standards trap that Georgiadou et al. (2004) mention is the lack of applications. The development of a large and expensive geographic database without a specific focus on information needs most often drives down to a deadend. In GIS-BH, this drive towards applications was present since the beginning.

Application is the key for knowledge that is engaged and leads to development. The path to this kind of knowledge has to include both practical knowledge and theoretical knowledge. In our case study, techne corresponds to the knowledge held by the technicians that dealt with cartography and urban cadastre, including the creation of digital maps, data maintenance, and the release of a final product to the public. Episteme is represented by the team that was in charge of studying and deploying the GIS, formed by specialists in various fields. In order to achieve phronesis, a surrounding background had to be present. This role was played by the emphasis on applications, with the obvious help of the fortunate combination of cartography, urban cadastre, and IT in the same corporate environment, which proved to be a decisive factor. Applications provided a common background for these teams, guiding the data acquisition and treatment efforts as much as guiding knowledge acquisition and technological development. 
The application-driven nature of the project can be seen in three examples. First, Prodabel was a company that had as a mission to develop applications for the local government of Belo Horizonte. Therefore, application was in its nature. All the technology developed and controlled by the company had only one objective, which was to provide services to the city.

Second, the cartography and urban cadastre department had also a mission of service. It was the main source of cartographic data for the city. It had a long standing tradition of providing maps that include applications ranging from solving legal disputes to address matching and the record of the distribution of physical resources.

Finally, the first large application of the project after that creation of the database, namely the compatibilization of street codes, required the establishment of a standard for data exchange. Here the difference was that the standard was not a thing in itself, and had a very direct purpose. The main objective was the exchange of home and business addresses. The focus on real data that was used to complement each other's databases did not let the standard become ineffective. On the contrary, all the participants were engaged and actively exchanged data and helped updating each other's databases, generating a good starting point for other cooperation initiatives.

\section{Lessons Learned: Recommendations for Similar Projects}

The GIS-BH project has become successful due to a combination of factors. Some of these factors are related to local characteristics and political context. In particular, the need to update the municipal cartography, simultaneously with the political interest in developing the city's information systems, provided a good opportunity for the creation of a project with broad objectives. Funding was also facilitated in this politically favorable context, and the need for political justification for expenditures in IT and database formation helped to guide the project towards application-specific goals, thus making it clear that IT is being regarded as means to an end. We understand that, while these conditions may not be immediately available in every context, there must be a serious concern with (1) funding sources, (2) political visibility, and (3) application-based justification for the investment.

Some factors of success, however, are general enough to serve as a basis for the proposition of a set of recommendations and assessment criteria for similar projects, both ongoing and initiatives that have to start from scratch. We divided these recommendations into three categories: applications, cooperation, and people.

- Applications: When determining the information needs of applications, focus on data that can potentially be shared among other applications. The maintenance of such data is likely to be critical. The data requirements of the applications must drive the maintenance efforts. Maintenance methodology must be developed from previous (non-digital) practices, using local knowledge, experience, and expertise. The intended users for the applications must also participate in the process, as specialists in the field related to the application (see below). 
- Cooperation: From the selection of applications and the determination of their information needs, identify potential partners for data sharing and cooperation in the development of data sets. Such partners will conceive their own applications, and the inter-organizational demand for some information classes will be important for the stability of the entire information system. Partners should not be forced to use the same technological tools or products; this decision should take into consideration the specific needs of the applications envisioned by the partner. Data sharing should not be format- or product-specific. If at all possible, sharing of existing data should be at no cost. Cost sharing for further data collection needs to take into consideration maintenance costs and effort, which may also be shared; this means that an organization that commits to provide maintenance to a class of data can be relieved of their share of the cost of initial data collection. It also means that cost-sharing agreements should be made considering aspects of budgeting, investment capacity, political calendar and others that are specific to each participating organization. In a formal multilateral cooperation agreement, rules should be flexible enough to allow the inclusion of new partners.

- People: Team formation and preparation must take into consideration that most GIS- and SDI-related efforts are multidisciplinary. Therefore, teams must include specialists from different fields, and the flexibility to admit new members depending on the requirements of each task. Leadership within the team must also be flexible, in order to give the specialist in the field that is closer to the problem at hand more leeway in the search for its solution. Team members must not only focus on learning how to operate the tools, but also need to understand the scientific and technological foundations of GIS and SDI. It is also important to systematically record and disseminate the results achieved in each step of the way, both internally and externally to reinforce political support.

We observe that projects that have definite application concerns and clear objectives as to their societal contribution have less difficulty in obtaining funding, gaining political support, and achieving the kind of visibility that ensures continuation. We also observe that projects that materialize intra-departmental or inter-organizational cooperation have a lower risk of discontinuity for political or financial reasons. Therefore, projects that are ongoing or that are about to be started should consider reviewing their objectives and intended relationships with other organizations with a focus on sustainability, considering the points we presented here.

\section{Conclusions and Future Work}

In this paper we described a GIS project, GIS-BH, which, even though it has started with a focus that often leads to failure (data and standards), managed to survive and end up generating a strong and active spatial data infrastructure for the city of Belo Horizonte, Brazil. The reasons for success were manifold, but we highlighted here the applicationdriven nature of the project. Also, the combination of multiple disciplines and multiple levels of expertise (ranging from practical to theoretical) was fundamental for the generation of applications and agreements that answered the information needs of the 
local community. We used Gadamer's and Habermas's insights into understanding and knowledge to explain some of the reasons that made the GIS-BH project become a foundation for Belo Horizonte's SDI.

While participating in the development and expansion of GIS-BH, we have spent most of the last fifteen years in the privileged position of a nationally-known project, thus being able to observe similar projects succeed and fail for various reasons. Even though we do not have a rigorous analysis of the causes for success and failure in such projects, we observe that failure is more common among projects which have started with a definite tax collection bias, while success rates seem to be higher among multidisciplinary and multipurpose projects.

While empirical, this observation enables us to say, from experience, that much of the driving force behind Belo Horizonte's GIS has originated in the demand posed by real applications, conceived and implemented to address real needs. That was the result of a combination of sensible thinking on the part of the managers that started and supported the project in its early stages, and clearly established paradigms, such as no-cost data distribution, extensive partnerships, and diversity of applications. We observe that this course of action can equally apply to both transitional and developed economies, since its success is mostly due to reaching wide agreements on principles and practices, always guided by real needs and applications.

The future of GIS-BH is clearly related to the development and deployment of services. In the past, the project has evolved from data sharing using proprietary format files to neutral interchange formats, and then on to Internet-based raw data distribution, and to a database-centric interoperable approach. The combination of the various kinds of demands that GIS-BH currently fulfills naturally leads to a service-oriented SDI (Bernard and Craglia 2005). In the process, the current role of metadata must be expanded and enhanced, and spatial ontologies can be used to facilitate consensus building on themes related to cooperation and on-line data sharing.

\section{References}

Bernard, L. and M. Craglia (2005). SDI: From Spatial Data Infrastructure to Service Driven Infrastructure. Research Workshop on Cross-Learning between Spatial Data Infrastructures (SDI) and Information Infrastructures (II), Enschede, Holanda.

Bernstein, R. J. (1983). Beyond Objectivisim and Relativism: Science, Hermeneutics, and Praxis. Philadelphia, University of Pennsylvania Press.

Borges, K. A. V., C. A. Davis Jr., et al. (2001). "OMT-G: an object-oriented data model for geographic applications." GeoInformatica 5(3): 221-260.

Braa, J., E. Monteiro, et al. (2004). "Networks of Action: Sustainable Health Information Systems across Developing Countries.” MIS Quarterly 28(3): 337-362.

Davis Jr., C. A. (1993). Address base creation using raster-vector integration. Urban and Regional Information Systems Association Annual Conference (URISA'93), Atlanta, Georgia. 
Davis Jr., C. A. (1995). Interchange of Geographical Information (in Portuguese). Belo Horizonte, PRODABEL.

Davis Jr., C. A. (2002). Geographical Information Interchange: the experience on standardization and cooperation in Minas Gerais state (in Portuguese). Geographic Data: aspects and perspectives. G. C. Pereira and M. C. F. Rocha. Salvador (BA), Rede Baiana de Tecnologias da Informação Espacial (REBATE): 43-54.

Davis Jr., C. A. and K. A. V. Borges (1994). Object-oriented GIS in practice. Urban and Regional Information Systems Association Annual Conference (URISA'94), Milwaukee, Wisconsin.

Davis Jr., C. A. and P. A. Oliveira (2002). "Interoperable and distributed GIS for large local governments (in Portuguese)." Informática Pública 4(1): 121-141.

Davis Jr., C. A. and C. A. Zuppo (1995). Updating urban geographic databases: methodology and challenges. Geographic Information Systems / Land Information Systems 1995 Annual Conference, Nashville, Tennessee.

Fonseca, F. T. and C. A. Davis Jr. (1999). Using the Internet to access geographic information: an Open GIS interface prototype. Interoperating Geographic Information Systems. M. E. Goodchild, M. J. Egenhofer, R. Fegeas and C. Kottman, Kluwer Academic Publishers.

Fonseca, F. T., M. J. Egenhofer, et al. (2000). "Ontologies and knowledge sharing in urban GIS.” Computers, Environment and Urban Systems 24(3): 251-272.

Fonseca, F. T., M. J. Egenhofer, et al. (2002). "Semantic granularity in ontology-driven geographic information systems." Annals of Mathematics and Artificial Intelligence 36(1-2): 121-151.

Fonseca, F. T. and C. A. Zuppo (1994). School pre-registration and student allocation. Urban and Regional Information Systems Association Annual Conference (URISA'94), Milwaukee, Wisconsin.

Gadamer, H.-G. (1975). Truth and Method. New York, Seabury Press.

Georgiadou, Y., S. Sahay, et al. (2004). Implementation of Spatial Data Infrastructures (SDI) in Transitional Economies. Omaha, NE, College of Information Science \& Technology, University of Nebraska at Omaha.

Habermas, J. (1971). Knowledge and Human Interests. Boston, Beacon Press.

Meinberg, F. F. (2003). "Tools for the analysis of traffic accidents using GIS (in Portuguese)." Informática Pública 5(1): 79-99.

Oliveira, M. P. G. (1997). Spatial decision support systems: models for analyzing the densification of economic activities in urban space (in Portuguese). Minas Gerais Government School. Belo Horizonte (MG), Fundação João Pinheiro.

Oliveira, S. M., R. P. Sousa, et al. (1995). A review of the limits of urban census sectors and other urban spatial reference units (in Portuguese). XVII Brazilian Cartographic Conference, Salvador (BA). 
Oliveira, S. M., R. P. Sousa, et al. (1996). "GIS in the definition of spatial reference units for Belo Horizonte's urban quality of living indicator (in Portuguese)." EspaçoBH 1(0): 21-29.

Peixoto, N. M. A. (2000). Methodology for the creation and compatibilization of a legalized parceling base map for the city of Belo Horizonte (in Portuguese). Minas Gerais Government School. Belo Horizonte (MG), João Pinheiro Foundation.

Pessanha, J. E. M. and F. R. Carvalho (1999). "Creation of an information system based on methods standardization for zoonosis control in the city of Belo Horizonte (in Portuguese).” Informática Pública 1(1): 63-74.

Pinto, M. V. (1999). "School pre-registration: democratization of the access to public education (in Portuguese).” Informática Pública 1(2): 139-156.

Reed, A. M. (2000). Rethinking Development as Knowledge: Implications for Human Development. Rome, United Nations Office for Project Services.

Sagasti, F. R. (2004). Knowledge and Innovation for Development: The Sisyphus Challenge of the 21st Century. Cheltenham, UK; Northhampton, MA, Edward Elgar.

Silva, T. E. P. P. and M. V. Ottoni (1995). The importance of cartography for the success of GIS deployment in the city of Belo Horizonte (in Portuguese). XVII Brazilian Cartographic Conference, Salvador (BA).

Sousa, R. P. and N. L. Bretas (1994). GIS in the surveillance of infant mortality of poor areas in a two-million-people city. Urban and Regional Information Systems Association Annual Conference (URISA'94), Milwaukee, Wisconsin.

The World Bank (1999). World Development Report - Knowledge for Development. New York, Oxford University Press.

Zuppo, C. A., C. A. Davis Jr., et al. (1996). GIS in the transportation and traffic systems of Belo Horizonte (in Portuguese). GIS Brasil 96, Curitiba (PR). 